ORIGINAL ARTICLE

\title{
Serum DDT, age at menarche, and abnormal menstrual cycle length
}

\author{
F Ouyang, M J Perry, S A Venners, C Chen, B Wang, F Yang, Z Fang, T Zang, L Wang, X Xu, \\ $X$ Wang
}

Occup Environ Med 2005;62:878-884. doi: 10.1136/oem.2005.020248

See end of article for authors' affiliations

.....................

Correspondence to: Dr M Perry, Department of Environmental Health Harvard School of Public Health, 665 Huntington Avenue, Building 1, Room 1413, Boston, MA 02115, USA; mperry@ hsph.harvard.edu

Accepted 13 June 2005 Background: Although dichlorodiphenyl trichloroethane (DDT) exposure is known to affect human
endocrine function, few previous studies have investigated the effects of DDT exposure on age at menarche or menstrual cycle length.

Methods: A cross sectional study was conducted to study the effects of DDT exposure on age at menarche and menstrual cycle length among 466 newly married, nulliparous female Chinese textile workers aged 20-34 years enrolled between 1996 and 1998. Serum was analysed for DDT and its major metabolites. Multivariate linear regression was used to estimate DDT exposure effects on age at menarche and multivariate logistic regression was used to estimate DDT exposure effects on odds of experiencing short or long cycles.

Results: Relative to those in the lowest DDT quartile, the adjusted mean age at menarche was younger in those in the fourth quartile ( -1.11 years). Modeled as a continuous variable, a $10 \mathrm{ng} / \mathrm{g}$ increase in serum DDT concentration was associated with an adjusted reduction in age at menarche of 0.20 years. Relative to those in the lowest DDT quartile, odds of any short cycle $(<21$ days) in the previous year were higher for those in the fourth quartile (odds ratio $=2.78 ; 95 \% \mathrm{Cl} 1.07$ to 7.14 ). There were no associations between serum DDT concentrations and odds of experiencing a long cycle ( $>40$ days).

Conclusion: Results suggest that DDT exposure was associated with earlier age at menarche and increased risk of experiencing a shortened menstrual cycle.
O ver the past 40 years, substantial evidence has surfaced on the hormone-like effects of some environmental contaminants (including certain pesticides) in fish, wildlife, and humans. ${ }^{1-3}$ Dichlorodiphenyl trichloroethane (DDT) was the first intentionally released chemical found to be an endocrine disrupter. ${ }^{45}$ Dichlorodiphenyl dichloroethene (DDE), the major and stable metabolite of DDT, has also been recognised as an endocrine disrupter. ${ }^{5}$ DDT, first manufactured on a large scale in 1945, was widely used throughout the United States and Europe from just after World War II through the 1970s to control insects on agricultural crops and insects that carry diseases such as malaria and typhus. DDT was also heavily used in China in the 1960s and 1970s. DDT was banned in the US in 1972, and banned in China in the early 1980s. However, DDT is still used in several areas of the world primarily in malaria control programmes. Because of their chemical stability, lipophilic nature, and propensity to bioaccumulate, DDT and its primary metabolite, DDE, remain ubiquitous contaminants of various environmental media, foods, and human adipose tissue despite bans on its use. ${ }^{1}$ DDE residues have been found in detectable amounts in all human populations monitored to date. $^{6} 7$

DDT and DDE are structurally similar to various steroid hormones, including oestrogens, and may interact with hormone functions thereby raising concerns about their potential toxicity via endocrine disruption. Both animal and in vitro studies support the hypothesis that DDT, its metabolites, and related compounds are potentially important human reproductive toxins. ${ }^{8}$ The onset of menarche (initiation of the first menstrual cycle) indicates the near completion of normal female sexual development. Too frequent periods, known as polymenorrhea, are typically defined as menstrual periods that occur more frequently than every 21 days. Conversely, oligomenorrhea, or infrequent menstruation, is generally defined as periods that occur 40 or more days apart. ${ }^{9}$ Both the onset of menarche and regular menstrual cycles require the finely tuned hormone signaling and integrated action of the hypothalamus-pituitary-ovarian axis. ${ }^{9}{ }^{10}$

A few studies have recently examined certain polychlorinated biphenyls (PCBs) and their effects on menstrual cycle length. Two studies reported a positive association between dietary PCB exposure and shortened menstrual cycle, ${ }^{11}{ }^{12}$ and one study reported no association with menstrual cycle length among women who ingested PCB contaminated fish oil in Taiwan. ${ }^{13}$

Although DDT/DDE is an endocrine disrupter, and maturation of the reproductive system and its normal function in adult women are regulated by the endocrine system, ${ }^{14-16}$ no previous studies have investigated women's DDT/DDE exposure and effects on their age at menarche. Only two studies have examined associations between DDT exposure and women's menstrual cycles, and both studied women in the US. One study in 50 women examined serum DDT exposure and abnormal menstrual cycle length and reported that high DDT/DDE exposure was associated with decreased cycle length. ${ }^{17}$ The other study in 55 female farm workers who experienced occupational pesticide exposure found that mean serum $\mathrm{p}, \mathrm{p}^{\prime}$-DDT levels were twice as high in women who complained of menstrual irregularities; however these differences were not statistically significant (mean $\mathrm{p}, \mathrm{p}^{\prime}$-DDT $3.0 v 1.57$ parts per billion of serum, $\mathrm{p}>0.05$ ). This study also noted that the most frequent medical complaint of the

Abbreviations: $\mathrm{BMl}$, body mass index; $\mathrm{DDE}$, dichlorodiphenyl dichloroethene; DDT, dichlorodiphenyl trichloroethane; FSH, follicle stimulating hormone; $M D L$, method detection limit 


\begin{tabular}{|c|c|c|c|}
\hline & $\begin{array}{l}\text { Participant } \\
(n=466)\end{array}$ & $\begin{array}{l}\text { Non-participant } \\
(\mathrm{n}=495)\end{array}$ & p Value ${ }^{*}$ \\
\hline \multicolumn{4}{|l|}{ Mean (SD) } \\
\hline Age (years) & $24.9(1.6)$ & $24.8(1.7)$ & 0.267 \\
\hline Height $(\mathrm{cm})$ & $157.6(5.1)$ & $157.8(4.7)$ & 0.538 \\
\hline Weight (kg) & $49.2(5.7)$ & $49.5(5.5)$ & 0.524 \\
\hline BMI $\left(\mathrm{kg} / \mathrm{m}^{2}\right)$ & $19.8(2.0)$ & $19.9(2.1)$ & 0.675 \\
\hline Birth year (years) & 1973 (2) & $1973(2)$ & 0.316 \\
\hline \multicolumn{4}{|l|}{ Education, n (\%) } \\
\hline Less than high school & $301(64.6)$ & $321(64.8)$ & \\
\hline High school+ & $165(35.4)$ & $174(35.2)$ & 0.988 \\
\hline \multicolumn{4}{|l|}{ Husband smokes, n (\%) } \\
\hline No & $192(42.0)$ & $191(40.1)$ & \\
\hline Yes & $265(58.0)$ & $285(59.9)$ & 0.604 \\
\hline
\end{tabular}

women in the prior four summers was menstrual irregularity. $^{18}$

In this report, we investigate age of menarche and abnormal menstrual cycle length in relation to serum DDT concentrations in a cohort of Chinese women.

\section{METHODS}

\section{Study population}

This study was part of a large prospective study of reproductive health conducted from 1996-98 in textile mills in Anhui, China. The study protocols were approved by the Human Subject Committee of the affiliated Chinese institutions and by the Institutional Review Boards of the Harvard School of Public Health and the Children's Memorial Hospital. All women provided written informed consent.

Detailed descriptions of the study population and data collection methods have been reported previously. ${ }^{19}$ Briefly, the eligibility criteria for women in the field enrollment were as follows: ${ }^{1}$ full time employment; ${ }^{2}$ aged $20-34$ years; ${ }^{3}$ newly married; and ${ }^{4}$ had obtained state permission to have a child.
All of the women were nulliparous textile workers and were not occupationally exposed to pesticides. At baseline, each subject completed a physical exam that included providing a blood sample and completed an interview concerning demographic information, age at menarche, menstrual information, and reproductive history. The follow up portion of the study involved providing diaries and urine samples. Beginning from the date of stopping any contraceptive method and attempting to conceive, each woman kept a daily diary to record sexual intercourse, vaginal bleeding, medication, and medical conditions and collected daily firstmorning urine specimens for 12 months or until a pregnancy was clinically confirmed, whichever came first. A total of 961 were enrolled at baseline and 567 completed the follow up. Baseline serum DDT was measured only among women who completed the follow up portion of the study. One hundred and one women did not have serum available for DDT analysis. This report includes the 466 women who completed the baseline interview and who had serum DDT data available. Demographic and exposure characteristics were compared between the 466 who completed the follow up and had baseline serum DDT data available and the 495 who either did not complete the follow up or who did not have DDT data available. Results showed there were no significant differences between the 466 who completed follow up and the 495 who enrolled at baseline but were not included in our study (table 1 ).

Among the 466 study subjects, one reported current alcohol use; one reported having ever experienced spontaneous abortion; 50 reported having ever experienced induced abortion; 15 reported having ever used oral contraceptives; and two reported having ever used an IUD. We studied the association of DDT/DDE and abnormal menstrual length in our study subjects by both including and excluding these 64 women who reported alcohol use, or spontaneous abortion, or induced abortion, or oral contraceptives, or using an IUD, which may have potentially influenced menstrual cycle length.

Table 2 Characteristics of 466 non-smoking, nulliparous female textile workers in Anhui, China, by serum total DDT concentrations

\begin{tabular}{|c|c|c|c|c|c|}
\hline & \multicolumn{5}{|c|}{ Serum total DDT } \\
\hline & $\begin{array}{l}\text { 1st quartile } \\
\text { (low) }\end{array}$ & 2nd quartile & 3rd quartile & $\begin{array}{l}\text { 4th quartile } \\
\text { (high) }\end{array}$ & Total \\
\hline $\begin{array}{l}\text { Sample size } \\
\text { Serum total DDT }(\mathrm{ng} / \mathrm{g})\end{array}$ & 116 & 117 & 117 & 116 & 466 \\
\hline $\begin{array}{l}\text { Range } \\
\text { Mean (SD) }\end{array}$ & $\begin{array}{l}5.52-19.2 \\
13.5(3.6)\end{array}$ & $\begin{array}{l}19.2-27.8 \\
23.5(2.5)\end{array}$ & $\begin{array}{l}27.8-41.2 \\
34.0(4.0)\end{array}$ & $\begin{array}{l}41.6-113 \\
57.1(13.9)\end{array}$ & $\begin{array}{l}5.52-113 \\
32.0(17.8)\end{array}$ \\
\hline$p, p^{\prime}-D D T(n g / g)$ & & & & & \\
\hline $\begin{array}{l}\text { Range } \\
\text { Mean (SD) }\end{array}$ & $\begin{array}{l}0.4-2.2 \\
2.2(1.0)\end{array}$ & $\begin{array}{l}0.5-3.2 \\
1.4(0.6)\end{array}$ & $\begin{array}{l}0.6-5.6 \\
1.8(0.9)\end{array}$ & $\begin{array}{l}0.9-13.1 \\
3.0(1.8)\end{array}$ & $\begin{array}{l}0.4-13.1 \\
1.8(1.3)\end{array}$ \\
\hline$p, p^{\prime}-D D E(n g / g)$ & & & & & \\
\hline $\begin{array}{l}\text { Range } \\
\text { Mean (SD) }\end{array}$ & $\begin{array}{l}4.8-17.8 \\
12.1(3.4)\end{array}$ & $\begin{array}{l}15.9-26.8 \\
21.8(2.5)\end{array}$ & $\begin{array}{l}25.2-39.6 \\
31.7(3.9)\end{array}$ & $\begin{array}{l}38.3-97.5 \\
53.3(12.9)\end{array}$ & $\begin{array}{l}4.8-97.5 \\
29.7(16.8)\end{array}$ \\
\hline$p, p^{\prime}-D D T / p, p^{\prime}-D D E(\%)^{*}$ & & & & & \\
\hline $\begin{array}{l}\text { Range } \\
\text { Mean (SD) }\end{array}$ & $\begin{array}{l}2.8-25.1 \\
8.3(3.8)\end{array}$ & $\begin{array}{l}2.0-16.1 \\
6.3(2.9)\end{array}$ & $\begin{array}{l}1.6-22.4 \\
5.7(2.9)\end{array}$ & $\begin{array}{l}1.6-18 \\
5.7(2.9)\end{array}$ & $1.6-25.1$ \\
\hline $\begin{array}{l}\text { Mean (SD) } \\
\text { Age (years), mean (SD) }\end{array}$ & $\begin{array}{l}8.3(3.8) \\
24.5(1.3)\end{array}$ & $\begin{array}{l}6.3(2.9) \\
24.8(1.5)\end{array}$ & $\begin{array}{l}5.7(2.9) \\
25.0(1.5)\end{array}$ & $\begin{array}{l}5.7(2.9) \\
25.3(1.9)\end{array}$ & $\begin{array}{l}6.5(3.3) \\
24.9(1.6)\end{array}$ \\
\hline Height $(\mathrm{cm})$, mean (SD) & $157.6(4.6)$ & $157.8(5.3)$ & $157.4(5.0)$ & $157.5(5.4)$ & $157.6(5.1)$ \\
\hline Weight $(\mathrm{kg})$, mean (SD) & $50.1(5.6)$ & $49.2(5.3)$ & $49.8(6.2)$ & $47.8(5.4)$ & $49.2(5.7)$ \\
\hline $\begin{array}{l}\text { Body mass index }\left(\mathrm{kg} / \mathrm{m}^{2}\right) \text {, } \\
\text { mean (SD) }\end{array}$ & $20.1(1.9)$ & $19.8(1.9)$ & $20.1(2.1)$ & $19.3(1.8)$ & $19.8(2.0)$ \\
\hline $\begin{array}{l}\text { Education, } n \text { (\%) } \\
\text { Middle or below }\end{array}$ & $83(71.6)$ & $76(65.0)$ & $66(56.4)$ & $76(65.5)$ & $301(64.6)$ \\
\hline High or above & $33(28.4)$ & $41(35.0)$ & $51(43.6)$ & 40 (34.5) & 165 (35.4) \\
\hline $\begin{array}{l}\text { Exposed to passive smoking, } \\
\mathrm{n}(\%)\end{array}$ & & & & & \\
\hline No & $61(53.0)$ & $47(40.2)$ & $46(40.4)$ & $39(34.8)$ & $193(42.1)$ \\
\hline Yes & $54(47.0)$ & $70(59.8)$ & $68(59.6)$ & $73(65.2)$ & $265(57.9)$ \\
\hline
\end{tabular}


Table 3 Crude and adjusted associations of serum total DDT with age at menarche

\begin{tabular}{|c|c|c|c|c|}
\hline \multirow[b]{2}{*}{ Exposures } & \multicolumn{4}{|c|}{ Age at menarche (years) } \\
\hline & $\mathbf{n}$ & Mean (SD) & Crude $\beta(95 \% \mathrm{Cl})$ & Adjusted $^{*} \beta(95 \% \mathrm{Cl})$ \\
\hline $\begin{array}{l}\text { DDT (ng/g) } \\
\text { 1 st quartile (5.5-19.2) } \\
\text { 2nd quartile (19.2-27.8) } \\
\text { 3rd quartile (27.8-41.2) } \\
\text { 4th quartile }(41.2-113.3 \text { ) } \\
\text { Trend } \\
\text { Linear DDT (per } 10 \mathrm{ng} / \mathrm{g})\end{array}$ & $\begin{array}{l}116 \\
117 \\
117 \\
116 \\
466 \\
466\end{array}$ & $\begin{array}{l}15.0(1.4) \\
14.6(1.4) \\
14.8(1.6) \\
14.2(1.3) \\
14.7(1.5)\end{array}$ & $\begin{array}{l}\text { Reference } \\
-0.42(-0.79 \text { to }-0.05) \\
-0.27(-0.64 \text { to } 0.10) \\
-0.80(-1.17 \text { to }-0.43) \\
p<0.001 \\
-0.14(-0.22 \text { to }-0.06)\end{array}$ & $\begin{array}{l}\text { Reference } \\
-0.55(-0.91 \text { to }-0.18) \dagger \\
-0.40(-0.78 \text { to }-0.03) \ddagger \\
-1.11(-1.50 \text { to }-0.72) \S \\
p<0.001 \\
-0.20(-0.28 \text { to }-0.13) \S\end{array}$ \\
\hline $\begin{array}{l}{ }^{*} \text { Adjusted for birth year, BMI } \\
+p<0.01 \\
\neq p<0.05 \\
\S p<0.001\end{array}$ & & & & \\
\hline
\end{tabular}

\section{Assessment of age of menarche and abnormal menstrual cycle length}

Information on age of menarche and abnormal menstrual cycle length was obtained from the baseline interview. The age at menarche was defined as the response to the question, "How old were you when you had your first menstrual period?" Women were asked questions about menstrual cycles during the past year to determine whether they had experienced menstrual cycles of abnormal length in the year before baseline. Short cycle was defined as a "yes" response to the question, "Did you have menstrual cycles lasting less than 21 days in the last year?", and the reference group for this analysis included women who responded "no". Long cycle was defined as a "yes" response to the question, "Did you have menstrual cycles lasting more than 40 days in the last year?", and the reference group included women who responded "no". Six women reported having experienced both a long cycle and a short cycle in the year before and were included as experiencing short cycle in the short cycle analysis and as experiencing long cycle in the long cycle analysis.

\section{Potential confounders}

Detailed information was collected during the baseline interview on various potential confounders including age, body weight and height, education, active and passive smoking, alcohol use, ever spontaneous or induced abortion, ever oral contraceptive use, and ever IUD use.

\section{Laboratory assays}

At baseline, each subject provided a non-fasting blood sample. Serum fractions were frozen at $-20^{\circ} \mathrm{C}$ until extraction. Serum samples were analysed by the Harvard School of Public Health Organic Chemistry Laboratory (Boston, MA, USA) for $\mathrm{p}, \mathrm{p}^{\prime}$ - and o, $\mathrm{p}^{\prime}$-isomers of DDT, DDE, and DDD and 67 individual polychlorinated biphenyl congeners and their sum. Total DDT $=\mathrm{p}, \mathrm{p}^{\prime}-\mathrm{DDT}+\mathrm{p}, \mathrm{p}^{\prime}-\mathrm{DDE}+\mathrm{p}, \mathrm{p}^{\prime}-\mathrm{DDD}+\mathrm{o}, \mathrm{p}^{\prime}-\mathrm{DDT}$ $+o, p^{\prime}$-DDE. Details of the laboratory analytic methods and quality control procedures are reported elsewhere. ${ }^{20}$ Briefly, gas chromatographic analyses of serum extracts employed electron capture detection and capillary columns of different polarity for primary and confirmatory analyses of all samples. Quantitation was based on the response factor of each analyte relative to an internal standard. Samples were processed in 27 batches of 18 serum samples accompanied by the following quality control samples: a procedural blank, matrix spike samples and an aliquot of laboratory control sample to assess interbatch laboratory coefficients of variation. Before extraction, each serum sample was spiked with the surrogate compounds, PCB congeners 30 and 112, to monitor the efficiency of the extraction procedure. The lipid content of each serum sample was not measured because the sample volume was insufficient $(0.5 \mathrm{ml})$.

The method detection limits (MDLs) for $\mathrm{p}, \mathrm{p}^{\prime}$-DDE and $\mathrm{p}, \mathrm{p}^{\prime}$-DDT were 0.022 and $0.031 \mathrm{ng} / \mathrm{g}$, respectively, and for other DDT compounds they were $0.01 \mathrm{ng} / \mathrm{g}$ or below. They were calculated as three times the standard deviation of mean levels in 27 procedural blanks analysed during the study. ${ }^{21}$ With the exception of $\mathrm{p}, \mathrm{p}^{\prime}$-DDD, the mean (SD) recoveries for all DDT compounds in matrix spike samples ranged from $95 \%$ to $101 \%$ with standard deviations below $5 \%$. The recovery of p, $\mathrm{p}^{\prime}$-DDD was 46 (6) \% (mean (SD)), and sample concentrations of $\mathrm{p}, \mathrm{p}^{\prime}$-DDD were corrected by per cent recoveries in matrix spikes analysed with the batch. All other DDT compounds were not corrected for recovery. The mean relative percent difference (\%RPD) between two matrix spike duplicates for all DDT compounds was 7\% or below.

Interbatch analytical precision was evaluated by analysing aliquots of bovine serum spiked at $0.1 \mathrm{ng} / \mathrm{g}$ to $4 \mathrm{ng} / \mathrm{g}$, to create the levels similar to the study samples. The interbatch coefficients of variation (CV\%) for p,p-DDE was $4 \%$ and for all other DDT compounds were $10 \%$ or below.

\begin{tabular}{|c|c|c|c|}
\hline \multirow[b]{2}{*}{ Exposures } & \multicolumn{3}{|c|}{ Short menstrual cycle } \\
\hline & n (\%) & Crude OR $(95 \% \mathrm{Cl})$ & 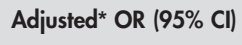 \\
\hline \multicolumn{4}{|l|}{ DDT $(\mathrm{ng} / \mathrm{g})$} \\
\hline 1st quartile (low) ( $n=116)$ & $7(6.0)$ & 1.00 (reference) & 1.00 (reference) \\
\hline 2nd quartile $(n=117)$ & $9(7.7)$ & $1.30(0.47$ to 3.61$)$ & 1.15 (0.41 to 3.23$)$ \\
\hline 3rd quartile $(n=117)$ & $12(10.3)$ & $1.78(0.68$ to 4.69$)$ & $1.71(0.64$ to 4.60$)$ \\
\hline 4th quartile (high) $(n=116)$ & $21(18.1)$ & $3.44(1.40$ to 8.45$)$ & $2.78(1.07$ to 7.14$)$ \\
\hline Trend & & $p=0.003$ & $p=0.016$ \\
\hline Linear DDT (per $10 \mathrm{ng} / \mathrm{g}$ ) & $49(10.5)$ & $1.21(1.04$ to 1.40$)$ & $1.16(0.99$ to 1.36$)$ \\
\hline
\end{tabular}


Table 5 Crude and adjusted associations of serum total DDT with any long menstrual cycle ( $>40$ days) in the year before

\begin{tabular}{|c|c|c|c|}
\hline \multirow[b]{2}{*}{ Exposures } & \multirow[b]{2}{*}{$n(\%)$} & \multicolumn{2}{|l|}{ Long cycle } \\
\hline & & Crude OR $(95 \% \mathrm{Cl})$ & Adjusted $^{*}$ OR $(95 \% \mathrm{Cl})$ \\
\hline \multicolumn{4}{|l|}{ DDT (ng/g) } \\
\hline 1st quartile (low) ( $n=116$ ) & $13(11.2)$ & 1.00 (reference) & 1.00 (reference) \\
\hline $2 n d$ quartile $(n=117)$ & $7(6.0)$ & $0.50(0.19$ to 1.31$)$ & $0.50(0.19$ to 1.36$)$ \\
\hline 3rd quartile $(n=117)$ & 15 (12.8) & $1.16(0.53$ to 2.57$)$ & $1.06(0.45$ to 2.48$)$ \\
\hline 4th quartile (high) $(n=116)$ & $6(5.2)$ & $0.43(0.16$ to 1.18$)$ & $0.49(0.17$ to 1.41$)$ \\
\hline Trend $(n=466)$ & & $p=0.34$ & $p=0.46$ \\
\hline Linear DDT (per $10 \mathrm{ng} / \mathrm{g}$ ) & $41(8.8)$ & 0.91 (0.75 to 1.10 ) & $0.92(0.74$ to 1.14$)$ \\
\hline
\end{tabular}

\section{Statistical analyses}

The outcome variables in this study were age at menarche, short cycle, and long cycle. Because the total mass of DDT isomers and metabolites was mostly comprised of $\mathrm{p}, \mathrm{p}^{\prime}$-DDE, we examined total serum DDT and $\mathrm{p}, \mathrm{p}^{\prime}$-DDE as major exposure variables, which were analysed both as continuous variables and as categorical variables in quartiles. We grouped study women into quartiles of equal sample size based on serum concentrations of total DDT and p, $\mathrm{p}^{\prime}$-DDE. For the age at menarche analyses, residuals were normally distributed in the final multivariate linear regression model, and age at menarche was used untransformed in the models. The first (lowest) quartile group was used as the reference group, and the association of age at menarche with DDT and $\mathrm{p}, \mathrm{p}^{\prime}$-DDE was estimated using linear regression models with and without adjustment for the potential confounders of birth year and BMI. Partial regression residual plots that modeled separate equations for BMI and birth year were used to choose the proper form of BMI and birth year in the final model. Because there were no predictable patterns in the residual plots the linear terms were used in the final model. Using total serum DDT or $\mathrm{p}, \mathrm{p}^{\prime}$-DDE as continuous variables, we estimated the association of a $10 \mathrm{ng} / \mathrm{g}$ unit increase on age at menarche in years. We conducted a trend test using a single ordinal variable in a linear regression model that was coded $0,1,2$, or 3 for the first, second, third, and fourth quartiles respectively.

We used logistic regression to investigate the odds of abnormal menstrual cycle length (either short cycle or long cycle) in the second, third, and fourth total serum DDT or $\mathrm{p}, \mathrm{p}^{\prime}$-DDE quartiles relative to the first (lowest) quartile, with and without adjustment for clinically relevant variables or potential confounders. Backward elimination logistic regression was used to choose model covariates from the candidate variables which included age, age squared, BMI, BMI squared, education, and passive smoke exposure. The variables with a p value equal to or less than 0.10 were included. The final adjusted model included age, age squared, BMI, education, and passive smoke exposure. We conducted a trend test using a single ordinal variable in a logistic regression model that was coded $0,1,2$, or 3 for the first, second, third, and fourth quartiles respectively. We also estimated the relative odds of short or long cycle associated with a $10 \mathrm{ng} / \mathrm{g}$ increase in serum total DDT or p, $\mathrm{p}^{\prime}$-DDE.

There were 382 subjects who reported having experienced neither a long cycle nor a short cycle in the year before. We also examined the association of DDT/DDE and short cycle between these 382 subjects and the 43 subjects with short cycle but without long cycle, and we examined the association of DDT/DDE and long cycle between these 382 subjects and 35 subjects with long cycle but without short cycle.

Because $\mathrm{p}, \mathrm{p}^{\prime}$-DDE and total DDT were highly correlated (Spearman correlation coefficient $=0.998$ ), and because the findings were very similar for total DDT and p, $\mathrm{p}^{\prime}$-DDE, data are only presented for total DDT in this report.

The ratio between $\mathrm{p}, \mathrm{p}$-DDT and p,p-DDE was calculated as $\mathrm{p}, \mathrm{p}^{\prime}-\mathrm{DDT} / \mathrm{p}, \mathrm{p}^{\prime}-\mathrm{DDE}(\%)=\left(\mathrm{p}, \mathrm{p}^{\prime}-\mathrm{DDT} / \mathrm{p}, \mathrm{p}^{\prime}-\mathrm{DDE}\right) \times 100$. The potential influence of the ratio of $p, p-D D T / p, p-D D E$ was assessed in models exploring main effect, effect modification (stratified by hi/lo p,p-DDT/p,p-DDE ratio), and interaction with DDT for each of the three outcomes (age at menarche, short cycle, long cycle).

\section{RESULTS}

\section{Characteristics of the study population}

All subjects were non-smokers. Table 2 shows characteristics of the 466 study subjects subdivided into four groups by quartiles of serum DDT. Age, weight, BMI, the ratio of $\mathrm{p}, \mathrm{p}^{\prime}$ $\mathrm{DDT} / \mathrm{p}, \mathrm{p}^{\prime}$-DDE $(\%)$ (ANOVA $\left.\mathrm{p}<0.05\right)$, and passive smoke exposure $\left(\chi^{2}\right.$ test $\left.\mathrm{p}<0.05\right)$ were significantly different among the DDT level quartile groups.

\section{Association of serum DDT with age at menarche}

The mean age at menarche was younger in the group with high serum DDT (table 3). Relative to women in the lowest quartile of serum DDT and after adjustment for important covariates, those in the highest quartile had lower mean age at menarche ( $\beta=-1.11$ years). Modeled as a continuous variable, a $10 \mathrm{ng} / \mathrm{g}$ increase in serum DDT concentration was associated with an adjusted reduction in age at menarche of 0.20 years.

\section{Association of serum DDT with short cycle}

Table 4 shows that the prevalence of short cycle increased as serum DDT level increased by quartiles. Relative to women in the lowest quartile of serum DDT and after adjustment for important covariates, those in the highest quartile had higher odds of experiencing a short cycle in the previous year $(\mathrm{OR}=2.78 ; 95 \%$ CI 1.07 to 7.14$)$. Modeled as a continuous variable, a $10 \mathrm{ng} / \mathrm{g}$ increase in serum DDT concentration was associated with increased odds of short cycle (OR $=1.16$; 95\% CI 0.99 to 1.36 ).

After excluding 64 women who reported alcohol use, or spontaneous abortion, or induced abortion, or oral contraceptive use, or IUD use, we repeated the same analyses on association of serum DDT with short cycle. Association of serum DDT (4th $v$ lst quartile adjusted OR $=5.80 ; 95 \%$ CI 1.58 to 21.28 ) with short cycle was stronger than the crude and adjusted models that included these 64 women (data not shown).

In another subgroup analysis comparing 43 subjects with short cycle but without long cycle in the year before with the 382 who experienced neither a long cycle nor a short cycle, we repeated the same analyses on the association of serum DDT with short cycle. The association of serum DDT (4th $v$ lst quartile, crude OR $=3.38,95 \%$ CI 1.29 to 8.83 , trend test 
$\mathrm{p}=0.005 ;$ adjusted $\mathrm{OR}=2.56,95 \%$ CI 0.93 to 7.04 , trend test $\mathrm{p}=0.029$ ) with short cycle was similar as crude and adjusted models in table 4.

\section{Association of serum DDT and $p, p^{\prime}-D D E$ with long cycle}

The same analyses as for short cycle were performed estimating the relation between DDT and long cycle. There were no associations between serum DDT concentrations and long cycle (table 5 ).

After excluding 64 women who reported alcohol use, or spontaneous abortion, or induced abortion, or oral contraceptive use, or IUD use, we repeated the same analyses on the association of the serum DDT with long cycle. The association of serum DDT with long cycle was similar in the analysis including and excluding these 64 women (data not shown).

In another subgroup analysis comparing 35 subjects with long cycle but without short cycle in the year before with the 382 who experienced neither a long cycle nor a short cycle, we repeated the same analyses on association of serum DDT with long cycle. The association of serum DDT with long cycle (crude trend test, $\mathrm{p}=0.293$; adjusted trend test, $\mathrm{p}=0.351$ ) was similar as crude and adjusted models in table 4 (data not shown).

The p,p-DDT/p,p-DDE ratio was not significantly associated with any of the three outcomes, and none of the models including the ratio changed our findings.

\section{DISCUSSION}

In this study, we demonstrated an association between serum DDT and p, $\mathrm{p}^{\prime}$-DDE concentration and age at menarche and any experience of a short menstrual cycle in the year before. We found that higher serum DDT and p, $\mathrm{p}^{\prime}-\mathrm{DDE}$ concentrations were associated with younger age at menarche, and that higher serum DDT and $\mathrm{p}, \mathrm{p}^{\prime}$-DDE were associated with greater risk of experiencing a short menstrual cycle. The short cycle associations were even stronger after we excluded women who drank alcohol, used oral contraceptives or an IUD, or ever experienced abortion. Our results appear to be robust and persistent even after adjustment for other important covariates, including after adjusting for birth year and BMI in the age at menarche analysis.

Our study is consistent with previous investigations and lends further support to previous studies that show DDT and DDE can affect female reproduction. One previous study suggested that higher DDE exposure in utero was associated with younger age at menarche among 151 women. But the DDE association with age at menarche was no longer significant in this study when controlling for estimated body size at menarche in a subsample of 102 women. ${ }^{22}$

Our findings appear to be biologically plausible. The onset of menarche indicates the near completion of normal sexual development and mature ovulation function of the ovary. $\mathrm{P}, \mathrm{p}^{\prime}$-DDE can act as an endocrine disruptor ${ }^{23}$ in several ways: through the steroidogenic pathway, ${ }^{24}$ as an androgen receptor antagonist; ${ }^{25}$ and acting independently to mimic the effects of androgen or oestrogen. ${ }^{26}$ It is possible that DDE accelerates the maturation of oocytes. p, $\mathrm{p}^{\prime}$-DDE alone or its combination with follicle stimulating hormone (FSH) increases aromatase activity of human granulosa cells. ${ }^{24}$ It can cause an increase of locally produced oestradiol since the granulosa cells under the influence of FSH can aromatise androgens to oestrogens..$^{27}$ The oestradiol:testosterone ratio is strictly controlled during follicular development and is closely related to the developmental potential of human oocytes, ${ }^{28}$ and oestradiol plays a pivotal role in oocyte maturation. ${ }^{29}$ The length and regularity of the menstrual cycle can be influenced by factors affecting the hypothalamus-pituitary-ovarian axis. ${ }^{10}$ Menstrual cycle length and regularity for example can indicate cumulative exposure to ovarian steroids ${ }^{10}$ and short cycles are common in women using oral contraceptives. ${ }^{9}$

Our findings may have important public health implications. In this study participants were aged 21-34 years when their blood samples were collected in 1998. DDT was widely used in China until it was banned in 1984. Participants were exposed to relatively high DDT levels from 7-21 years, from birth to 1984. Our finding that DDT exposure was associated with an earlier age at menarche raises an important public health question, namely, does environmental DDT or $\mathrm{p}, \mathrm{p}^{\prime}$ DDE contribute to the increasing prevalence of earlier puberty in children and adolescents observed worldwide including in China $?^{30}$ In the US, average age of menarche in middle class American girls fell from about 15.5 years a century ago to about 12.5 today. ${ }^{9}$ If the answer is yes, then what influence will this effect have on overall human reproductive health? By the same token, our finding of an association between DDT exposure and shortened menstrual cycles raises the question of what influence would increased prevalence of short menstrual cycles have on women's reproductive and general health? These questions appear difficult to answer without a better understanding of whether shortened menstrual cycles directly influence population fertility rates. Nonetheless, even slight effects on normal reproductive function by exogenous chemicals such as DDT should be of concern and warrant further research attention.

This study had two major advantages. Firstly, this was a relatively homogenous population. The study subjects were young, healthy, non-smoking, and nulliparous. Their nulliparous status rules out the possibility they had experienced lactation, which is known to reduce women's DDT or DDE adipose and serum levels. ${ }^{731}$ Also, our study subjects were aged 21-34 years old and were not close to either end of their ovulatory years. Irregular menstrual cycles are most common at both ends of a woman's fertile period (that is, the first five years following menarche and during perimenopause). Additionally they were all textile workers and the major occupational exposures were dust and noise. Exposures to DDT and its metabolites in this study population were nonoccupational and thus unlikely to be confounded by concomitant exposure to non-persistent pesticides. Also, serum PCB levels were very low in our study subjects (mean $0.15 \mathrm{ng} / \mathrm{g}$, SD $0.10 \mathrm{ng} / \mathrm{g}$ ). So our results were unlikely to have been confounded by PCB exposure.

Secondly, our exposure variables were based on objective measurements of total DDT and p, $\mathrm{p}^{\prime}$-DDE levels in individual serum samples. DDT and its metabolites are stored most readily in fatty tissue and slowly released from storage sites, with an average half life in the body of 10 years. ${ }^{7}$ Heavy exposure to DDT in this population should have ended when DDT was banned in 1984. Therefore serum measurements should accurately represent the body burden of DDT and its metabolites during the previous year (when short or long cycles occurred). Similarly, blood samples were collected on average 10.2 (SD 2.1) years after the onset of menarche in the study women. Given the long half life of DDT and its metabolites in the body, it is plausible that the serum measurements in this study were comparable to relative body burdens at the time of menarche. If there was any measurement error, it is most likely that the DDT levels at the time of study enrollment underestimated the relative DDT body burdens at the time of menarche. Although the $\mathrm{p}, \mathrm{p}-\mathrm{DDT} / \mathrm{p}, \mathrm{p}-\mathrm{DDE}$ ratio has been interpreted as an indicator of exposure timing, our results did not show an association between the ratio and our outcomes of interest.

Several limitations need to be taken into account when interpreting the results of this study. Firstly, age at menarche was self reported in our study and there is a potential for 
recall bias. In our study, the median time between onset of menarche and study interview was 10 years (range 5-19 years). However, moderate to high correlations between actual and recalled menarche have been reported for females up to 19 years after the event. ${ }^{32}$ Furthermore, because serum DDT or DDE was measured after the completion of the field study, and women were not aware of their serum DDT or DDE levels, any recall bias, if it existed, would most likely have introduced a non-differential misclassification bias. Greater BMI values are associated with earlier menarche onset. ${ }^{33}{ }^{34}$ Current BMI was used as a covariate in the DDT or DDE and age at menarche analyses because of a lack of accurate BMI data at the time of menarche. However, this was a relatively homogenous population with little BMI variability (mean BMI 19.8 (SD 2.0) $\mathrm{kg} / \mathrm{m}^{2}$ ) and extreme differences between adolescent and young adult BMI would not be expected.

Secondly, short and long cycles in the previous year were retrospectively recalled. Again, any recall bias, if it existed, would most likely have been non-differential and would have tended to bias our findings toward no effect. Early pregnancy loss was not laboratory measured in our current study. However, this condition would have most likely resulted in extended menstrual cycles, and there was no evidence of an association between DDT exposure and long menstrual cycle in this study both including and excluding those who ever experienced induced abortion and spontaneous abortion.

Another limitation is that lipid content of the serum was not measured because serum volume was insufficient. In general, serum DDT levels will be overestimated in individuals with higher, compared with lower, serum lipid levels when concentrations are expressed on a wet weight basis (as in our study). Therefore, if serum lipids at study time were causally associated with either age at menarche or short cycle, this would potentially bias our results. But we found no previous publications that reported associations between serum lipid concentration and age at menarche or menstrual cycle length. And, because this was a young, healthy population with little BMI variability and no obesity, the primary source of serum lipid variability would have been from recent dietary sources. However, it is unlikely that fasting status at the time of blood draw or the lipid content of recently consumed foods would correlate with age at menarche or risk of abnormal menstrual cycle length. Thus, any measurement bias, if it existed, would most likely have been non-differential and tended to bias our results toward a finding of no association.

Finally, the serum level of DDT and DDE in this study population is relatively high as compared to that in the current US population. Although we demonstrated an exposureresponse relation, caution is needed in generalising our findings to other populations with low level DDT or DDE exposure.

In summary, our results suggest that earlier age of menarche is associated with high serum DDT and p, $\mathrm{p}^{\prime}$-DDE exposure, and that there is an increased risk of short cycle in association with high serum DDT and p, $\mathrm{p}^{\prime}$-DDE exposure.

\section{ACKNOWLEDGEMENTS}

This study is supported in part by grants 1R01 HD32505 from the National Institute of Child Health and Human Development; IR01 ES08337, ES-00002, P01 ES06198, and 1R01 ES11682 from the National Institute of Environmental Health Science; and 20-FY980701 and 20-FY02-56 from the March of Dimes Birth Defects Foundation, USA.

\section{Authors' affiliations}

F Ouyang, M J Perry, S A Venners, C Chen, B Wang, X Xu, Department of Environmental Health, Harvard School of Public Health, Boston, MA, USA
F Ouyang, Department of Epidemiology, School of Public Health, Fudan University, Shanghai, China

F Yang, Z Fang, T Zang, Institute for Biomedicine, Anhui Medical University, Anhui, China

L Wang, Center for Ecogenetics and Reproductive Health, Beijing Medical University, Beiijing, China

X Wang, Mary Ann J Milburn Smith Child Health Research Program, Department of Pediatrics, Northwestern University Feinberg School of Medicine and Children's Memorial Hospital and Children's Memorial Research Center, Chicago, IL, USA

\section{REFERENCES}

1 Colborn T, vom Saal FS, Soto AM. Developmental effects of endocrinedisrupting chemicals in wildlife and humans. Environ Health Perspect 1993;101:378-84.

2 Kavlock RJ, Daston GP, DeRosa C, et al. Research needs for the risk assessment of health and environmental effects of endocrine disruptors: a report of the US EPA-sponsored workshop. Environ Health Perspect 1996; 104(Suppl 4):715-40.

3 Sonnenschein C, Soto AM. An updated review of environmental estrogen and androgen mimics and antagonists. J Steroid Biochem Mol Biol 1998;65:143-50

4 Davis DL, Bradlow $\mathrm{HL}$. Can environmental estrogens cause breast cancer? Sci Am 1995;273:167-72.

5 Jaga $\mathrm{K}$. What are the implications of the interaction between DDT and estrogen receptors in the body? Med Hypotheses 2000;54:18-25.

6 Murphy R, Harvey C. Residues and metabolites of selected persistent halogenated hydrocarbons in blood specimens from a general population survey. Environ Health Perspect 1985;60:115-20.

7 US DHHS. Toxicological profile for DDT/DDD/DDE (update). In: US Department of Health, Human Services phs, Agency for Toxic Substances, Disease Registry, eds. 2000: 4, 5, 218, 223).

8 Turusov V, Rakitsky V, Tomatis L. Dichlorodiphenyltrichloroethane (DDT): ubiquity, persistence, and risks. Environ Health Perspect 2002;110:125-8.

9 Carlson KJ, Eisenstat SA, Ziporyn T. The new Harvard guide to women's health. Cambridge, MA: Harvard University Press, 2004.

10 Harlow SD, Ephross SA. Epidemiology of menstruation and its relevance to women's health. Epidemiol Rev 1995; 17:265-86.

11 Axmon A, Rylander L, Stromberg U, et al. Altered menstrual cycles in women with a high dietary intake of persistent organochlorine compounds. Chemosphere 2004;56:813-19.

12 Mendola P, Buck GM, Sever LE, et al. Consumption of PCB-contaminated freshwater fish and shortened menstrual cycle length. Am J Epidemiol 1997; 146:955-60.

13 Yu ML, Guo YL, Hsu CC, et al. Menstruation and reproduction in women with polychlorinated biphenyl (PCB) poisoning: long-term follow-up interviews of the women from the Taiwan Yucheng cohort. Int J Epidemiol 2000;29:672-7.

14 Apter D, Vihko R. Premenarcheal endocrine changes in relation to age at menarche. Clin Endocrinol (Oxf) 1985;22:753-60.

15 Landgren BM, Unden AL, Diczfalusy E. Hormonal profile of the cycle in 68 normally menstruating women. Acta Endocrinol (Copenh) 1980;94:89-98.

16 Legro RS, Lin HM, Demers LM, et al. Rapid maturation of the reproductive axis during perimenarche independent of body composition. J Clin Endocrinol Metab 2000:85:1021-5.

17 Windham G, Mitchell P, Petreas M, et al. Exposure to DDT and metabolites in relation to menstrual cycle length among Laotian immigrants. Epidemiology 2002;13:S198.

18 Chase HP, Barnett SE, Welch NN, et al. Pesticides and U.S. farm labor families. Rocky Mt Med J 1973;70:27-31

19 Wang X, Chen C, Wang L, et al. Conception, early pregnancy loss, and time to clinical pregnancy: a population-based prospective study. Fertil Steril 2003;79:577-84.

20 Korrick SA, Altshul LM, Tolbert PE, et al. Measurement of PCBs, DDE, and hexachlorobenzene in cord blood from infants born in towns adjacent to a PCB-contaminated waste site. J Expo Anal Environ Epidemiol 2000;10:743-54

21 Korrick SA, Chen C, Damokosh Al, et al. Association of DDT with spontaneous abortion: a case-control study. Ann Epidemiol 2001;11:491-6.

22 Vasiliu O, Muttineni J, Karmaus W. In utero exposure to organochlorines and age at menarche. Hum Reprod 2004;19:1506-12.

23 Cooper RL, Kavlock RJ. Endocrine disruptors and reproductive development: a weight-of-evidence overview. J Endocrinol 1997;152:159-66.

24 Younglai EV, Holloway AC, Lim GE, et al. Synergistic effects between FSH and 1,1-dichloro-2,2-bis(P-chlorophenyl)ethylene ( $\left.\mathrm{P}, \mathrm{P}^{\prime}-\mathrm{DDE}\right)$ on human granulosa cell aromatase activity. Hum Reprod 2004;19:1089-93.

25 Kelce WR, Stone CR, Laws SC, et al. Persistent DDT metabolite p, $\mathrm{p}^{\prime}-\mathrm{DDE}$ is a potent androgen receptor antagonist. Nature 1995;375:581-5.

26 Andersen HR, Vinggaard AM, Rasmussen TH, et al. Effects of currently used pesticides in assays for estrogenicity, androgenicity, and aromatase activity in vitro. Toxicol Appl Pharmacol 2002;179:1-12.

27 Hillier SG, Whitelaw PF, Smyth CD. Follicular oestrogen synthesis: the 'twocell, two-gonadotrophin' model revisited. Mol Cell Endocrinol 1994; 100:51-4.

28 Xia P, Younglai EV. Relationship between steroid concentrations in ovarian follicular fluid and oocyte morphology in patients undergoing intracytoplasmic sperm injection (ICSI) treatment. J Reprod Fertil 2000;1 18:229-33. 
29 Tesarik J, Mendoza C. Direct non-genomic effects of follicular steroids on maturing human oocytes: oestrogen versus androgen antagonism. Hum Reprod Update 1997;3:95-100.

$30 \mathrm{Ge}$ Q. Sexual precocity [in Chinese]. Sheng Zhi Yi Xue Za Zhi 2000;6:20-22.

31 Wong CK, Leung KM, Poon BH, et al. Organochlorine hydrocarbons in human breast milk collected in Hong Kong and Guangzhou. Arch Environ Contam Toxicol 2002;43:364-72.
32 Must A, Phillips SM, Naumova EN, et al. Recall of early menstrual history and menarcheal body size: after 30 years, how well do women remember? Am J Epidemiol 2002;155:672-9.

33 Styne DM. Puberty, obesity and ethnicity. Trends Endocrinol Metab 2004; 15:472-8.

34 Mandel D, Zimlichman E, Mimouni FB, et al. Age at menarche and body mass index: a population study. J Pediatr Endocrinol Metab 2004;17:1507-10. 